\title{
MEDEX2015: greater sea-level fitness is associated with lower sense of effort during Himalayan trekking without worse acute mountain sickness
}

Article

Accepted Version

Macdonald, J. H., Rossetti, G. M. K. ORCID:

https://orcid.org/0000-0002-9610-6066, Smith, M., Jackson, A. R., Callender, N., Newcombe, H. K., Storey, H. M., Willis, S., van den Beukel, J., Woodward, J., Pollard, J., Wood, B., Newton, V., Virian, J., Haswell, O. and Oliver, S. J. (2017) MEDEX2015: greater sea-level fitness is associated with lower sense of effort during Himalayan trekking without worse acute mountain sickness. High Altitude Medicine \& Biology, 18 (2). pp. 152-162. ISSN 1557-8682 doi:

https://doi.org/10.1089/ham.2016.0088 Available at https://centaur.reading.ac.uk/97687/

It is advisable to refer to the publisher's version if you intend to cite from the work. See Guidance on citing.

Published version at: https://doi.org/10.1089\%2Fham.2016.0088

To link to this article DOI: http://dx.doi.org/10.1089/ham.2016.0088

Publisher: Mary Ann Liebert Inc 
including copyright law. Copyright and IPR is retained by the creators or other copyright holders. Terms and conditions for use of this material are defined in the End User Agreement.

\section{www.reading.ac.uk/centaur}

\section{CentAUR}

Central Archive at the University of Reading

Reading's research outputs online 
1 This article was accepted in its current form to High Altitude Medicine \& Biology on $11^{\text {th }}$

2 February 2017.

3

4 MEDEX2015: Greater sea-level fitness is associated with lower sense of effort during Himalayan trekking

5 without worse Acute Mountain Sickness

6

7 Running head: Fitness, exercise and AMS at altitude

8

9

10

Gabriella M.K. Rossetti ${ }^{1,2}$, Jamie H. Macdonald ${ }^{1,2}$, Matthew Smith $^{2}$, Anna R. Jackson², Nigel Callender ${ }^{2}$,

11 Hannah K. Newcombe ${ }^{2}$, Heather M. Storey ${ }^{2}$, Sebastian Willis ${ }^{2}$, Jojanneke van den Beukel ${ }^{2}$, Jonathan

Woodward ${ }^{2}$, James Pollard², Benjamin Wood², Victoria Newton², Jana Virian², Owen Haswell², and Samuel J.

13 Oliver ${ }^{1,2}$

${ }^{1}$ Extremes Research Group, College of Health and Behavioural Sciences, Bangor University, Bangor, Gwynedd,

United Kingdom;

17

${ }^{2}$ Medical Expeditions, Pinfold, Hyssington, Montgomery, Powys, United Kingdom.

Address for correspondence:

Samuel J. Oliver PhD

22

College of Health and Behavioural Sciences,

23 Bangor University,

24 Bangor,

$25 \quad$ LL57 2PZ,

26 UK.

27 Email:

s.j.oliver@bangor.ac.uk 
29

30

31

32

33

34

35

36

37

38

39

40

41

42

43

44

45

46

47

48

49

50

51

\section{Abstract}

This study examined the complex relationships of fitness and hypoxic sensitivity with submaximal exercise responses and Acute Mountain Sickness (AMS) at altitude. Determining these relationships is necessary before fitness or hypoxic sensitivity tests can be recommended to appraise individuals' readiness for altitude. Forty-four trekkers (26 men; 18 women; 20-67 years) completed a loaded walking test and a fitness questionnaire in normoxia to measure and estimate sea-level maximal aerobic capacity $\left(\dot{\mathrm{V}}_{2 \max }\right)$, respectively. Participants also completed a hypoxic exercise test to determine hypoxic sensitivity (cardiac, ventilatory, and arterial oxygen saturation responses to acute hypoxia, $\mathrm{FiO}_{2}=0.112$ ). One month later all participants completed a three-week trek to $5085 \mathrm{~m}$ with the same ascent profile. On ascent to $5085 \mathrm{~m}$, ratings of perceived exertion ( $\mathrm{RPE}_{\text {ascent }}$ ), fatigue by Brunel Mood Scale, and AMS were recorded daily. At 5085m, RPE during a fixed workload step test ( $\mathrm{RPE}_{\text {fixed }}$ ) and step rate during perceptually-regulated exercise $\left(\mathrm{STEP}_{\mathrm{RPE} 35}\right)$ were recorded. Greater sea-level $\mathrm{V}_{2 \text { max }}$ was associated with, and predicted, lower sense of effort ( $\mathrm{RPE}_{\text {ascent }} r=-0.43 ; p<0.001$; $\mathrm{RPE}_{\mathrm{fixed}} ; r=-0.69 ; p<0.001$ ) and higher step rate $\left(\mathrm{STEP}_{\mathrm{RPE} 35} \mathrm{r}=0.62 ; \mathrm{p}<0.01\right)$, but not worse AMS $(r=0.13 ; p=0.4)$ or arterial oxygen desaturation $(r=0.07$; $p=0.7)$. Lower RPE $\mathrm{ascent}_{\text {was }}$ also associated with better mood, including less fatigue $(r=0.57 ; p<0.001)$. Hypoxic sensitivity was not associated with, and did not add to the prediction of submaximal exercise responses or AMS. In conclusion, participants with greater sea-level fitness reported less effort during simulated and actual trekking activities, had better mood (less fatigue), and chose a higher step rate during perceptually-regulated exercise, but did not suffer from worse AMS or arterial oxygen desaturation. Simple sea-level fitness tests may be used to aid preparation for high-altitude travel.

Key words: Maximal oxygen uptake, Exercise, Acute mountain sickness, Hypoxic ventilatory response, Arterial oxygen saturation 


\section{Introduction}

Many people travel to altitude for work and leisure including trekkers, military personnel, and miners (Government of Nepal, 2013). As well as high-altitude illness, fatigue presents a major psychophysiological risk factor for summit failure, injury, and fatality at altitude (Firth et al., 2008; Oliver et al., 2012). Recent commentaries in this and other journals highlight the potential importance of adequate sea-level fitness to reduce fatigue and therefore enhance altitude exercise performance, including trekking times and summit success (Bärtsch \& Swenson, 2013; Burtscher et al., 2015). However, the relationships between sea-level fitness, submaximal exercise responses at altitude, and Acute Mountain Sickness (AMS) are complex (MacInnis et al., 2015), and as yet unknown.

Numerous studies indicate that individuals with high sea-level maximal aerobic capacity $\left(\dot{\mathrm{V}}_{2 \max }\right.$ ) have high altitude $\dot{\mathrm{V}} \mathrm{O}_{2 \max }$ (Fulco et al., 1998). Yet there is evidence that the absolute loss of $\dot{\mathrm{V}} \mathrm{O}_{2 \max }$ in high-fit individuals is greater at high altitude than their less-fit counterparts (Ferretti et al., 1997; Marconi et al., 2004; Mollard et al., 2007). In fact, the decline in very high-fit individuals is so great at high altitude that their $\dot{\mathrm{V}} \mathrm{O}_{2 \max }$ is no different or even lower than their less-fit counterparts (MacInnis et al., 2015). Furthermore it is often assumed that individuals with high sea-level $\dot{\mathrm{V}}_{2 \max }$ have greater exercise performance. However, $\dot{\mathrm{V}}_{2 \max }$ is not the only determinant of long-duration submaximal exercise responses, and other measures of fitness, such as fractional utilization of $\dot{\mathrm{V}} \mathrm{O}_{2 \max }$ (e.g. ventilatory threshold) and economy, are potentially as important (Bassett \& Howley, 2000; Coyle et al., 1988). For trekking activities, which are typically submaximal, sense of effort during exercise (most often assessed by rating of perceived exertion; RPE) is also functionally important because it appraises the individual's comfort level. Sense of effort is also an essential component of general fatigue (Enoka \& Stuart, 1992). Despite the well-documented relationship between fitness and exercise performance at sea level, the relationship between sea-level fitness and sense of effort during submaximal exercise at altitude is unclear.

Even if high sea-level fitness is associated with greater exercise capacity and reduced sense of effort, this may be at the cost of exacerbating AMS. Indeed, regular endurance training has been identified as a risk factor for altitude illness (Karinen et al., 2010; Richalet et al., 2012). A possible explanation for this is that fitter individuals experience greater arterial desaturation with acute hypoxia even during submaximal exercise (Lhuissier et al., 2012), which is likely a result of greater cardiac output (Richalet \& Lhuissier, 2015), or an indirect effect of greater oxygen extraction in the muscle (Van Thienen \& Hespel, 2016). Alternatively, worse AMS may occur because 
fitter individuals exercise at a greater intensity at altitude and/or gain altitude quicker. These arguments provide possible reasons for the common anecdotal field observation of poorer than expected exercise performance and AMS in high-fit persons at high altitude. Despite the anecdotes and plausible physiological responses, evidence is lacking to explain the complex relationship between sea-level fitness, exercise, and AMS.

Some authors further advocate that hypoxic sensitivity is an important physiological factor determining altitude exercise performance (Schoene et al., 1984) and illness risk (Richalet \& Canouï-Poitrine, 2014). This has led to the development of various resting and exercising hypoxic sensitivity tests to predict altitude exercise performance and illness susceptibility (Lazio et al., 2010; Rathat et al., 1992). However these are not routinely implemented, perhaps due to a lack of clinically relevant discrimination at an individual level (Bärtsch, 2014), or due to their complexity and requirement for specialist equipment including a method to simulate a high-altitude environment.

In summary, the relationships of fitness and hypoxic sensitivity with sense of effort during submaximal exercise and AMS at altitude are complex and unknown. Determining these relationships is necessary before fitness or hypoxic sensitivity tests can be recommended to appraise individuals' readiness for altitude. Therefore, the first aim of this study was to explain the relationship of sea-level fitness with submaximal exercise responses (sense of effort during submaximal exercise and step rate during perceptually-regulated exercise) and AMS during chronic altitude exposure. The second aim was to determine the utility of sea-level fitness (as assessed by $\dot{\mathrm{V}}_{2 \max }$, ventilatory threshold, economy, and a simple questionnaire-based estimation of $\dot{\mathrm{V}}_{2 \max }$ ) and hypoxic exercise testing to predict submaximal exercise responses and AMS at altitude. Finally we aimed to determine whether physiological responses to hypoxia could explain the relationship between fitness and submaximal exercise responses. To this end, we assessed sea-level fitness and acute physiological responses to hypoxia $\left(\mathrm{FiO}_{2}=0.112\right.$; equivalent $5000 \mathrm{~m}$ ) one month before a three-week trek to the Manaslu Circuit in the Nepal Himalaya. On the trek, sense of effort during submaximal exercise was assessed during simulated and actual trekking activities and physiological responses to chronic hypoxia were assessed at Base Camp (5058 m). AMS was assessed daily. We hypothesized that high sea-level fitness would be associated with submaximal exercise responses (lower sense of effort during submaximal exercise and higher step rate during perceptually-regulated exercise) at altitude, without increased AMS. Second, we hypothesized that sea-level and hypoxic exercise tests would be significant predictors of submaximal exercise responses. Third, we hypothesised that hypoxic exercise tests would be significant predictors of AMS at altitude. 


\section{Materials and Methods}

\section{Participants and study design}

114 Forty-four trekkers, 26 men and 18 women (mean (SD): age 39 (14) yr, body mass 69.0 (14.5) kg, height 172 (10) $\mathrm{cm}$ ) from the MEDEX Manaslu trek volunteered for this observational cohort study. All participants were lowlanders, with an altitude of residence below $500 \mathrm{~m}$. Forty-one participants (93\%) had previously travelled to high altitude (>1500 m), and of these 41 participants, 32 (78\%) reported previous AMS, one (2\%) had a history of HACE, and none (0\%) had a history of HAPE. Nine (20\%) participants had a history of migraine (confirmed by a physician), three (7\%) were smokers, and average alcohol consumption was $81.0(63.4) \mathrm{g} \cdot$ week $^{-1}$. Self-report physical activity was assessed on a scale developed by Jackson and colleagues (1990), which ranged from 0 Avoids walking or exercise (e.g. always uses elevators, drives whenever possible instead of walking), to 7 - Runs more than 10 miles per week or spends more than 3 hours per week in comparable physical activity. Self-report physical activity ranged from 1-7, with mean of 5 (2), and $\dot{\mathrm{V}}_{2 \max }$, ranged from 29 to 62 with mean $45(8) \mathrm{mL} \cdot \mathrm{min}^{-}$

${ }^{1} \cdot \mathrm{kg}^{-1}$. The study received ethical approval from the North West Wales Research Ethics Committee and was conducted in accordance with the Declaration of Helsinki 2008. All volunteers provided written informed consent. Data were collected between February and April 2015. An overview of the study is depicted in Figure 1.

\section{Pre-trek experimental procedures}

One month before the trek participants completed assessments of sea-level fitness and hypoxic sensitivity. Participants were asked to refrain from exhaustive exercise, caffeine and alcohol for twelve hours before all tests.

Sea-level fitness ( $\dot{\mathrm{V}}_{2 \max }$, ventilatory threshold, and economy) was determined during a walking test to exhaustion on a motorized treadmill (H-P-Cosmos, Sports \& Medical GmbH; Nussdorf) with simultaneous gas analysis (Cortex Metalyzer, Biophysik GmbH; Leipzig). Participants wore a weighted rucksack (15 kg for men and 12.5 $\mathrm{kg}$ for women). The test consisted of $5 \mathrm{~km} \cdot \mathrm{h}^{-1}$ walking with a ramped increase in gradient from $5 \%$ to $25 \%$ over 18 minutes $\left(1.11 \% \cdot \min ^{-1}\right)$, followed by a ramped increase in speed $\left(0.67 \mathrm{~km} \cdot \mathrm{h}^{-1} \cdot \mathrm{min}^{-1}\right)$ thereafter. Rating of perceived exertion (RPE) was recorded each minute of the test using the Borg CR100 (Borg \& Borg, 2001). $\dot{\mathrm{V}} \mathrm{O}_{2 \max }$ was identified by two or more of the following criteria (Pescatello et al., 2013): volitional fatigue, a plateau in $\dot{\mathrm{V}}_{2}$ despite an increase in workload, respiratory exchange ratio $\geq 1.15$, heart rate $\geq 95 \%$ age-predicted heart rate maximum (220-age). $\dot{\mathrm{VO}}_{2 \max }$ was also predicted using the equation provided in Matthews et al. (1999). 
141 Ventilatory threshold was determined using the method outlined by Gaskill et al. (2001) and economy as $\dot{\mathrm{VO}}_{2}$ (in $\left.\mathrm{ml} \cdot \mathrm{kg}^{-1} \cdot \mathrm{min}^{-1}\right)$ at a gradient of $6 \%$.

144 Hypoxic sensitivity was determined using a modified version of the Richalet test (Richalet et al., 2012; CanouïPoitrine et al., 2014), with the exercise modality changed from cycling on an ergometer to stepping in time to a metronome, and the $\mathrm{FiO}_{2}$ chosen to match the specific demands of the expedition. Participants completed fixedworkload step tests in normoxia and hypoxia $\left(\mathrm{FiO}_{2}=0.112 ; 5000 \mathrm{~m}\right)$. Step tests were conducted in an environmental chamber (Hypoxico Inc; NY), separated by 1.5 to 3 hours. Each step test included: 4 min $30 \mathrm{~s}$ of seated rest and 4 min $30 \mathrm{~s}$ of exercise. During the exercise participants wore a $7 \mathrm{~kg}$ rucksack whilst stepping at 24 steps $\cdot \mathrm{min}^{-1}$ on a $21 \mathrm{~cm}$ step. Ventilation ( $\dot{\mathrm{VE}}$ ) was determined by collection of expired gases (Douglas bag system, Cranlea Ltd; Birmingham) for the final minute of exercise, and oxygen saturation $\left(\mathrm{SpO}_{2}\right)$ and heart rate were measured by a pulse oximeter (9550 OnyxII, Nonin Medical Inc; Minnesota) and a heart rate monitor (RS800CX; Polar UK; Warwick), and recorded in the final 30s of exercise. RPE was recorded in the final 30s for familiarization.

Hypoxic sensitivity was determined using equations described previously (Canouï-Poitrine et al., 2014; Richalet et al., 2012):

Where $\mathrm{SpO}_{2}$, Oxygen saturation; HR, Heart rate; $\mathrm{VE}$, Minute ventilation (L·min); EH, Exercise in hypoxia (baseline); EN, Exercise in normoxia (baseline); BM, Body mass (kg).

Trek experimental procedures

Participants arrived in Kathmandu $(1300 \mathrm{~m})$ and were transported to Arughat $(518 \mathrm{~m})$ by bus to begin the trek. The 44 participants travelled in five groups of mixed age, sex and sea-level fitness. Each group completed the Manaslu trekking itinerary, and therefore the same altitude profile, an ascent profile that is typical of other highaltitude treks (e.g. Dhaulagiri circuit). The ascent profile included four days trekking above $3000 \mathrm{~m}$, with two days of $\sim 300 \mathrm{~m}$ ascent per day and two days with $\sim 600 \mathrm{~m}$ ascent per day. They all completed the ascent to Base 
171

172

173

174

175

176

177

178

179

180

181

182

183

184

some locations. Participants abstained from prophylactic medication and all other medications taken were recorded but not restricted.

\section{Trekking Demands}

On each day of the trek physical and physiological demands were assessed, but for the benefit of clarity only data from the final day of trekking on ascent to Base Camp are presented. To assess physical demands, after breakfast, body mass was assessed by weighing participants in base layers using mechanical scales (Salter Housewares, Kent; UK); loaded weight was assessed by weighing participants in full trekking attire including boots and rucksack; and external weight was calculated by subtracting the body mass from the loaded mass. Participants were able to walk at their chosen pace and the start and end times of each individual's trekking day was recorded. The trekking route was tracked using a global satellite positioning system (GPS; inReach SE, Delorme, Yarmouth; ME). Energy expenditure (EE) was then calculated using an equation validated previously (Pandolf et al., 1977). Relative trekking intensity for the ascent to Base Camp was calculated as:

Relative trekking intensity $=\mathrm{RPE}_{\mathrm{ascent}} / \mathrm{EE}\left(\mathrm{kJ}^{-1} \cdot \mathrm{min}^{-1}\right)$

Where RPE $E_{\text {ascent, }}$ Session RPE (Fanchini et al., 2016) recorded 30 minutes after trekkers completed $6.3 \mathrm{~km}$ walking exercise from 4472 to 5085 m; EE, Energy expenditure (calculated from the equation provided in Pandolf et al., 1977).

To assess physiological demands, participants wore heart rate monitors (RS800CX, Polar, Warwick; UK) throughout the day's trek, and heart rate was averaged for the trekking session.

\section{Sense of effort during submaximal exercise}

To determine the relationship between sea-level fitness and sense of effort during submaximal exercise at altitude, we assessed sense of effort during submaximal exercise by recording RPE. RPE was recorded using the Borg CR100 (Borg \& Borg, 2001) which asks participants to rate the intensity of the exercise sensation using numbers from 0-100+ and verbal descriptors (e.g. "moderate", equivalent to 25). Extensive evidence supports the use of RPE as a valid and appropriate method to record sense of effort and perceptual responses to exercise (Eston, 2012). Sense of effort was determined from session RPE (Fanchini et al., 2016) recorded 30 minutes after trekkers completed $6.3 \mathrm{~km}$ walking exercise from 4472 to $5085 \mathrm{~m}$ (RPE ascent). Session RPE has been validated as a quantitative measure of exercise load (Foster et al., 2001). Participants also completed the Brunel Mood Scale (BRUMS; Terry et al., 1999) on arrival at Base Camp to determine the psychological effects of the exercise, 
201

202

203

204

205

206

207

208

209

210

211

212

213

214

215

216

217

218

219

220

221

222

223

224

225

226

227

228

229

230

including self-reported fatigue. To further determine sense of effort during submaximal exercise at altitude, all participants completed the fixed-workload step test the day after arriving at $5085 \mathrm{~m}$ (day 16-18 of the expedition), breathing altitude ambient air (549 (1) mbar) but otherwise using the same protocol as completed at sea level. Specifically, participants wore a $7 \mathrm{~kg}$ rucksack whilst stepping at $24 \mathrm{steps} \cdot \mathrm{min}^{-1}$ on a $21 \mathrm{~cm}$ step. The primary outcome variable for this test was $\mathrm{RPE}$ at $4 \mathrm{~min} 30 \mathrm{~s}$ of stepping ( $\mathrm{RPE}_{\text {fixed }}$ ). In addition, $\mathrm{SpO}_{2}$, heart rate, and minute ventilation (V்) were determined using methods as described for the sea-level step tests. Exercise ventilation reserve and ventilatory efficiency were calculated using equations adapted from Bernardi et al. (2006):

Exercise ventilation reserve $(\%)=\left(\left(\dot{\mathrm{V}} \mathrm{E}_{\max }-\dot{\mathrm{V}} \mathrm{E}_{\text {alt }}\right) / \dot{\mathrm{V}} \mathrm{E}_{\max }\right) \times 100$

Ventilatory efficiency $\left(\% \cdot \mathrm{L}^{-1} \cdot \mathrm{min}^{-1}\right)=\mathrm{SpO}_{2} / \dot{\mathrm{V}}_{\text {alt }}$

Where $\dot{\mathrm{V}} \mathrm{E}_{\max }$, Maximal exercising ventilation from sea-level $\dot{\mathrm{V}} \mathrm{O}_{2 \max }$ test; $\dot{\mathrm{V}} \mathrm{E}_{\text {alt }}$, Exercising ventilation during fixed-workload step test at altitude; $\mathrm{SpO}_{2}$, Oxygen saturation during fixed-workload step test at altitude.

Chronic change in heart rate was calculated as:

Chronic change in heart rate $(\mathrm{bpm})=\mathrm{HR}_{\mathrm{EN}}-\mathrm{HR}_{\mathrm{EA}}$

Where $\mathrm{HR}_{\mathrm{EN}}$, Heart rate during fixed-workload exercise in normoxia (baseline); $\mathrm{HR}_{\mathrm{EA}}$, Heart rate during fixedworkload step test at altitude (Base Camp, $5085 \mathrm{~m}$ ).

Immediately after the fixed-workload step test, submaximal exercise capacity was determined by assessing step rate during perceptually-regulated exercise $\left(\mathrm{STEP}_{\mathrm{RPE} 35}\right)$. This perceptually-regulated step rate test provided assessment of exercise production at a relative workload. Clamping RPE to produce self-paced exercise in this manner is a validated tool for determining functional and endurance exercise capacity (Coquart, Tabben, Farooq, Tourny, \& Eston, 2016; Eston, 2012). Each participant was asked to complete stepping exercise for four minutes at a step rate that was equivalent to an RPE of 35 (described on the RPE scale as "somewhat strong"). An RPE of 35 was chosen because it has been previously reported as the typical sensed effort of mountain walkers and workers (Ainslie et al., 2002; Callender et al., 2012). During this exercise participants were free to alter their step rate. In the final minute step rate $\left(\mathrm{STEP}_{\mathrm{RPE} 35}\right), \mathrm{HR}$, and $\mathrm{SpO}_{2}$ were recorded. For the purpose of familiarization, participants completed three practice trials (two in normoxia, one in acute hypoxia) that included familiarization with the CR100 scale and completing the entire stepping exercise. In a separate pilot study $(n=6)$, we showed that with three practice sessions this perceptually-regulated step rate test has good reliability, with intraclass correlation coefficient of 0.94 , coefficient of variation of $2.4 \%$, and limits of agreement bias and $95 \%$ confidence intervals (lower limit; upper limit) of $1.0(-1.5 ; 3.5) \mathrm{steps} \cdot \mathrm{min}^{-1}$. The perceptually-regulated step rate test also has 
231

232

233

234

235

236

237

238

239

240

241

242

243

244

245

246

247

248

249

250

251

252

253

254

255

256

257

258

259

good face validity, with trekkers and expedition leaders reporting that it was representative of their normal trekking pace.

Both step tests were repeated two days later (on the third day at Base Camp), in a sub-sample of 21 participants. The sub-sample was representative of whole study sample, with no difference in age, height, body mass, $\dot{\mathrm{V}}_{2 \max }$, or sex ratio (all $p \geq 0.5$ ).

\section{Acute Mountain Sickness (AMS)}

Each morning on the trek, participants recorded AMS symptoms using the Lake Louise Score (LLS; Roach et al., 1993) under the supervision of a researcher. From these symptoms clinically-defined AMS was identified when the participant was higher than $2500 \mathrm{~m}$, LLS total exceeded three or more, and headache with at least one other symptom was present. An individual with AMS at any point over the expedition was classified as AMS susceptible (AMS+); individuals without AMS over the expedition were classified as AMS resistant (AMS-). Percentage of days with AMS and peak LLS were also calculated.

\section{Statistical analysis}

The primary independent variable of fitness was sea-level $\dot{\mathrm{V}}_{2 \max }$ (extensive exploratory analyses revealed no additional benefit of the fitness variables ventilatory threshold or economy). The primary outcome variable of sense of effort during submaximal exercise was RPE recorded during the fixed workload test performed at high altitude (RPE fixed).

To determine the relationships between sea-level fitness with i) submaximal exercise responses at altitude ( $\mathrm{RPE}_{\text {fixed }}, \mathrm{RPE}_{\text {ascent }}$, and $\mathrm{STEP} \mathrm{RPE33}_{3}$; ii) acute physiological responses to hypoxia (HVRe, $\left.\mathrm{HCRe}, \Delta \mathrm{SpO}_{2} \mathrm{e}\right)$; iii) chronic physiological responses to hypoxia (exercise ventilation reserve, ventilatory efficiency, chronic change in heart rate, and $\mathrm{SpO}_{2}$ at altitude); iv) the percentage of trekking days with AMS, and peak AMS score, Pearson's correlations were used. For all correlational analyses, the strength of a relationship was determined by the $r$ value.

To determine whether hypoxic exercise testing significantly adds to sea-level fitness testing to predict sense of effort during submaximal exercise at altitude and AMS, hierarchical regression was used and $r^{2}$ change was 
reported. To determine the utility of $\dot{\mathrm{VO}}_{2 \max }$ and hypoxic sensitivity for predicting AMS susceptibility, Receiver Operating Characteristic curves were calculated and comparison of area under the curves (AUC) was completed.

263 To investigate whether classical physiological responses to hypoxia mechanistically explain the relationship 264 between fitness and sense of effort during submaximal exercise at altitude, ventilatory and cardiac responses to acute normobaric hypoxia (HVRe, HCRe) and chronic high-altitude exposure (chronic change in heart rate, exercise ventilation reserve, ventilatory efficiency), were investigated using a mediation analysis. Analysis was completed using the SPSS macro PROCESS (Hayes, 2013) with 5000 bootstrap samples. An indirect effect (evidence of a mechanistic explanation) was deemed significant if the upper and lower 95\% Confidence Interval limits of the size of the indirect path did not include zero.

271 A sample size estimation for the correlation between sea-level $\dot{\mathrm{V}}_{2 \max }$ and $\mathrm{RPE}_{\text {fixed }}$ indicated that 37 participants

272 would be needed to produce a $90 \%$ chance of obtaining statistical significance at the 0.05 level for a minimum important effect size of $r=0.5$ (Bland, 2015).

Diagnostic accuracy analyses were completed using MedCalc version 15.8 (MedCalc Software, Ostend;

276 Belgium), all other analyses were completed using SPSS version 22 (IBM Corp, Armonk; NY). Statistical significance was set at $p<0.05$ for all analyses. 


\section{Results}

\section{Trekking demands}

Physiological and perceptual responses to the submaximal step tests are shown in Table 1. Physical, physiological and perceptual demands of the final day's trek into Base Camp are shown in Table 2. The trekkers took 262 (52) min to complete the $6.3 \mathrm{~km}$ trek with $613 \mathrm{~m}$ altitude gain from 4472 to $5085 \mathrm{~m}$.

\section{Sea-level fitness and submaximal exercise responses at altitude}

Greater sea-level fitness was associated with lower sense of effort ( $\mathrm{RPE}_{\mathrm{fixed}}$ and $\left.\mathrm{RPE} \mathrm{Escent}\right)$ and higher step rate $\left(\mathrm{STEP}_{\mathrm{RPE} 35}\right)$ at altitude (Figure 2). Ascent time to Base Camp was not related to fitness $(r=-0.11 ; p=0.48$; Table 2). Therefore, fitter persons ascended with less sensed effort (lower RPE) but a similar walking speed compared to their less-fit counterparts. Lower RPE ascent was also associated with less negative mood (total mood disturbance; $r=0.50 ; p=0.001)$, specifically less fatigue $(r=0.57 ; p<0.001)$, tension $(r=0.40 ; p=0.01)$, and confusion $(r$ $=0.35 ; p=0.03)$. Lower RPE ascent was also associated with increased vigor, albeit weakly $(r=-0.28 ; p=0.09)$. Lower sense of effort and higher step rate in fitter individuals did not come at the cost of worse arterial oxygen saturation: sea-level $\dot{\mathrm{VO}}_{2 \max }$ was not related to $\mathrm{SpO}_{2}$ during the fixed-workload $(r=0.07 ; p=0.67)$ or perceptuallyregulated $(r=0.16 ; p=0.33)$ step tests at altitude.

\section{Acute Mountain Sickness (AMS)}

Twenty-five participants (61\%) had clinically-defined AMS at least once during the expedition. Of those with AMS, it lasted 4 (2) days. The highest incidence of AMS for a given day was 47\%, occurring on day one at Base Camp (5085 m). AMS was not related to any sea-level assessment variables. None of sea-level fitness, hypoxic sensitivity or physiological responses to chronic hypoxia was related to AMS susceptibility, percentage of days with AMS, or peak LLS ( $r=0.05$ to $0.26 ; p=0.12$ to 0.91 ; Figure 5 ). AUC were all below 0.70 , indicating poor diagnostic accuracy for all methods. Two (5\%) participants took acetazolamide in the treatment of AMS for one and eight days each, while 30 (68\%) participants took some form of analgesic medication, with 2.2 (1.9) days spent on analgesics across the whole sample. There was no relationship between fitness and number of days on acetazolamide $(r=-0.08 ; p=0.60)$ or analgesic medications $(r=0.20 ; p=0.22)$. 
307

308

309

310

311

312

313

314

315

316

317

318

319

320

321

322

323

324

325

326

327

328

329

330

331

332

333

334

335

336

In a sub-sample, the step tests were repeated on day three after participants' AMS symptoms had reduced (LLS decreased from 3.3 (2.5) to 2.1 (2.1); $p=0.06$ ), and sense of effort during submaximal exercise had decreased across the sub-sample (RPE fixed decreased from 57 (31) on day one to 44 (19) on day three; $p<0.01$ ). Submaximal step rate during perceptually-regulated exercise increased (STEP ${ }_{\mathrm{RPE} 35}$ increased from 26 (6) on day one to 28 (5) on day three; $p<0.01$ ). These adaptive changes (representative of enhanced acclimatization) did not affect the relationship between fitness and submaximal exercise responses, which were consistent with those observed on day one. Greater sea-level fitness was associated with lower $\mathrm{RPE}_{\mathrm{fixed}}$ on day three $(r=-0.75 ; p<0.001)$, and greater $\operatorname{STEP}_{\mathrm{RPE} 35}$ on day three $(r=0.70 ; p=0.001)$, and was not related to $\mathrm{SpO}_{2}$ during the fixed-workload $(r=$ $0.26 ; p=0.28$ ). Greater sea-level fitness tended to be associated with greater $\mathrm{SpO}_{2}$ during the perceptuallyregulated step test $(r=0.43 ; p=0.058)$, despite participants producing a higher absolute workload.

\section{Physiological Mechanisms}

Hypoxic sensitivity and submaximal exercise responses at altitude

Individuals with lower HVRe (Figure 3A) and higher HCRe (Figure 3B) had lower sense of effort compared to their counterparts. HVRe was positively related to $\operatorname{RPE}_{\text {fixed }}(r=0.38 ; p=0.02)$, and negatively related to $\mathrm{STEP}_{\mathrm{RPE} 35}$ $(r=-0.39 ; p=0.02)$. There was a weak negative relationship between HCRe and $\operatorname{RPE}_{\text {fixed }},(r=-0.31 ; p=0.07)$, but HCRe was not related to $\operatorname{STEP}_{\mathrm{RPE} 35}(r=0.19 ; p=0.26) . \Delta \mathrm{SpO}_{2} \mathrm{e}$ was not related to any measure of sense of effort at altitude ( $r=0.23$ to $0.25 ; p=0.15$ to 0.17 ).

\section{Physiological responses to chronic high altitude}

Individuals with less ventilatory stress at altitude (Figure 3C) and a greater cardiac response to chronic high altitude (Figure 3D) had lower sense of effort compared to their counterparts. Greater exercise ventilation reserve was associated with lower $\operatorname{RPE}_{\text {fixed }}(r=-0.61 ; p<0.001)$, and superior $\operatorname{STEP}_{\mathrm{RPE} 35}(r=0.44 ; p=0.01)$. Greater ventilatory efficiency was associated with lower $\operatorname{RPE}_{\text {fixed }}(r=-0.44 ; p=0.01)$, and superior $\operatorname{STEP}_{\text {RPE35 }}(r=0.44$; $p<0.001)$. A larger chronic change in heart rate was associated with lower $\operatorname{RPE}_{\text {fixed }}(r=-0.49 ; p<0.01)$, and superior $\operatorname{STEP}_{\mathrm{RPE} 35}(r=0.41 ; p=0.01)$.

\section{Mediation Analysis}

Cardiac parameters tended to explain (negatively mediate) the relationship between sea-level fitness and submaximal exercise sense of effort at altitude (Table 3). Hypoxic exercise ventilation reserve also tended to 
337 explain (positively mediate) the relationship between sea-level fitness and submaximal exercise sense of effort at 338 altitude. In contrast, exercise ventilation reserve and ventilatory efficiency did not mediate the relationship 339 between sea-level fitness and sense of effort during submaximal exercise at altitude.

\section{Utility of variables to predict submaximal exercise responses at altitude}

342 Matthews and colleagues' equation (1999) was used to calculate a simple questionnaire-based estimation of $343 \dot{\mathrm{V}}_{2 \max }$. The predicted values were closely related to the measured values from the maximal exercise test $(r=$ $3440.80 ; p<0.001)$. Furthermore, this simple fitness assessment negatively predicted sense of effort during 345 submaximal exercise at altitude $\left(\mathrm{RPE}_{\mathrm{fixed}}\right)$, albeit the prediction was significantly improved with the addition of 346 laboratory-assessed $\dot{\mathrm{V}}_{2 \max }$ (see table 4, analysis 1).

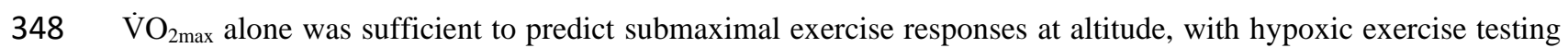
349 providing no additional benefit. Specifically, hypoxic sensitivity did not account for any additional variance than laboratory $\dot{\mathrm{V}}_{2 \max }$ when predicting sense of effort for $\mathrm{RPE}_{\text {fixed }}\left(r^{2}\right.$ change $=0.07 ; p=0.22$; see table 4 , analysis 2$)$, $\mathrm{RPE}_{\text {ascent }}\left(r^{2}\right.$ change $\left.=0.05 ; p=0.52\right)$, or STEP $\mathrm{RPE} 35_{(}\left(r^{2}\right.$ change $\left.=0.06 ; p=0.33\right)$. In addition, hypoxic sensitivity did not account for any additional variance than questionnaire-based estimation of $\dot{\mathrm{V}} \mathrm{O}_{2 \max }$ when predicting submaximal exercise responses for $\mathrm{RPE}_{\text {fixed }}\left(r^{2}\right.$ change $\left.=0.09 ; p=0.18\right), \mathrm{RPE}_{\text {ascent }}\left(r^{2}\right.$ change $\left.=0.06 ; p=0.48\right)$, or $\operatorname{STEP}_{\mathrm{RPE} 35}\left(r^{2}\right.$ change $\left.=0.09 ; p=0.26\right)$. 
355

356

357

358

359

360

361

362

363

364

365

366

367

368

369

370

371

372

373

374

375

376

377

378

379

380

381

382

383

384

\section{Discussion}

The primary findings of this study were that greater sea-level fitness is associated with lower sense of effort and higher step rate during perceptually-regulated exercise, but not worse AMS or arterial desaturation, We were able to demonstrate that these relationships are robust, and are not affected by acclimatization. Consequently, simple sea-level fitness tests predicted sense of effort during submaximal exercise at altitude, and no additional screening information was gained from hypoxic sensitivity testing.

Greater sea-level fitness was associated with lower sense of effort during an arduous trekking day, lower sense of effort during submaximal exercise, and a superior step rate during perceptually-regulated exercise (at the typical chosen effort of mountain walkers and workers) at altitude. Importantly, lower sense of effort during trekking was also associated with better mood, including less fatigue, tension and confusion. High fitness may therefore also protect against the major risk factors of musculoskeletal pain (Jakobsen et al., 2015), injury (Burtscher et al., 2015), and mortality (Firth et al., 2008), and enhance productivity in those travelling to altitude for work and leisure. Lower sense of effort and better mood indicates trekkers more comfortably met the demands of the trek, suggesting high fitness may also protect against summit failure and improve expedition enjoyment. Consequently, this study provides the first empirical evidence that simple sea-level fitness assessments may be useful to aid preparations for high-altitude travel. Further, it provides preliminary evidence to support the recommendation that individuals should complete cardiorespiratory training to improve aerobic fitness before high-altitude travel (Bärtsch \& Swenson, 2013). Aerobic training can improve $\dot{\mathrm{VO}}_{2 \max }$ by $\sim 20 \%$, although the response varies between 0-50\%, depending on genetics, age, initial fitness, and the exact training type (Bacon et al., 2013; Bouchard et al., 2011; Milanović et al., 2015). Aerobic fitness is therefore a factor that can be modified to the substantial benefit of those that travel to altitude for work or leisure. As higher fitness was not associated with greater AMS or arterial desaturation, we recommend increasing fitness as much as possible before altitude travel. But of course increased fitness should not be used to ascend more quickly than current guidelines, which would increase altitude illness risk.

The most useful variable to predict sense of effort during submaximal exercise at altitude was $\dot{\mathrm{V}} \mathrm{O}_{2 \max }$ as determined by laboratory maximal exercise testing. Even sea-level fitness $\left(\dot{\mathrm{V}} \mathrm{O}_{2 \max }\right)$ estimated by a short questionnaire collecting simple demographic information also provided a strong prediction of sense of effort at altitude. Since the addition of hypoxic sensitivity variables did not improve the prediction of sense of effort during 
385

386

387

388

389

390

391

392

393

394

395

396

397

398

399

400

401

402

403

404

405

406

407

408

409

410

411

412

413

submaximal exercise at altitude, it must be concluded that technically demanding hypoxic exercise testing has no additional benefit beyond simple fitness testing for screening individuals' readiness to perform at altitude. It must be acknowledged that this study used a modified version of Richalet's proposed test. However research by Richalet's group showed exercise intensity and $\mathrm{FiO}_{2}$ do not affect HVR or HCR obtained from the test (Lhuissier et al., 2012). Given the ease of administration (no arduous exercise or specialist equipment required), this simple questionnaire-based assessment of sea-level fitness provides medical and outdoor practitioners with a useful tool to help patients and clients prepare for altitude travel.

Importantly, lower sense of effort during submaximal exercise in fitter individuals did not come at the cost of worse altitude illness. Increased sea-level fitness was not a risk factor for AMS at altitude when ascent rate and trekking energy expenditure were similar in individuals. Additionally, in this study, all participants followed the same ascent profile. In contrast, previous studies to show a positive relationship between fitness and AMS have measured across multiple expeditions without accounting for differences in ascent rate (Karinen et al., 2010; Richalet et al., 2012). This suggests that any observed relationship between fitness and AMS is likely an artefact of behavioural differences. That is, fitter individuals likely ascend faster than their less-fit counterparts and it is this increased ascent rate that is responsible for their increased AMS (Schneider et al., 2002).

Physiological responses provided some explanation for the lower sense of effort during submaximal exercise in fitter individuals at altitude. Contrary to previous studies with acute hypoxic exposures, high-fit individuals had similar or better $\mathrm{SpO}_{2}$ than less-fit individuals during exercise tests completed at the high-altitude base camp on day one and three, respectively. This was accompanied by an elevated heart rate response and a lower ventilatory response to acute hypoxia and chronic altitude exposure. Thus, at steady state submaximal exercise (typical of that required during trekking), the lung was able to accommodate the increased cardiac output without compromising pulmonary gas exchange. It is not clear whether the lower ventilatory response in high-fit individuals is due to decreased chemosensitivity or a more efficient ventilatory system, but whatever the cause this response can be considered adaptive as it was associated with lower sense of effort during submaximal exercise. In support of this interpretation, hyperventilation is associated with increased work of breathing and dyspnea (Amann et al., 2007; Babb et al., 2008), which is a major determinant of RPE (Bernhadt et al., 2013). Increased work of breathing is particularly detrimental at altitude as it elevates peripheral and central fatigue 
414 (Ainslie \& Ogoh, 2010; Amann, 2012) by reducing locomotor and cerebral blood flow that occur to maintain

415 respiratory muscle demands (Amann et al., 2007).

\section{$417 \quad$ Limitations}

418 This study included no altitude measure of maximal exercise capacity, such as $\dot{\mathrm{V}} \mathrm{O}_{2 \max }$, time to exhaustion, or time trial tests. However, RPE during submaximal exercise is closely related to maximal exercise capacity (Eston, 2012; Coquart et al., 2014; Coquart et al., 2016). In addition, the assessment of maximal exercise capacity has limited functional relevance to the assessment of trekking and other submaximal work and exercise commonly performed at altitude. Due to their crucial role in fatigue (a major risk factor for mortality on high-altitude treks), we believe sense of effort and perceptually-regulated exercise are the best methods available to assess trekking exercise. This study provides preliminary evidence of the physiological mechanisms likely to explain the relationship between sea-level fitness and sense of effort during submaximal exercise at altitude. Future studies that experimentally manipulate fitness via training or other methods are required to confirm the importance of cardiorespiratory adaptations for submaximal exercise and fatigue at high altitude.

\section{Conclusion}

Understanding the determinants of exercise and illness at altitude is important to better prepare those who travel to high altitude (Puthon et al., 2015). This study indicates that greater sea-level fitness is related to lower sense of effort during submaximal exercise at altitude and better mood (less fatigue, tension and confusion). Importantly, the lower sense of effort during submaximal exercise in high-fit individuals did not come at the cost of worse AMS or greater arterial oxygen destauration. This study provides the first empirical evidence to support recent recommendations that people might complete sea-level aerobic fitness training before high-altitude travel (Bärtsch \& Swenson, 2013; Burtscher et al., 2015). Indeed, our data suggest low-fit persons may improve their trekking experience by increasing sea level fitness because it is associated with less effort and better mood during trekking at alttiude. The study also indicates that a sea-level fitness assessment could be used to aid preparation for highaltitude travel by enabling better aerobic exercise prescription and identifying those people who might might benefit most from the aerobic training. Given that fatigue and confusion are major risk factors for injury and fatality at altitude, sea-level fitness assessment and exercise training should be considered as part of preparations for high-altitude travel. 
Rossetti et al.

444 Disclosure statement

445 The authors of this article have no conflicts of interests to disclose.

446

447 Acknowledgements

448 MEDEX2015 research expedition comprised of many persons who without their help the study would not have

449 been possible. In particular, we would like to thank the expedition organizers and volunteers who participated in 450 this research, and also Kevin Williams, Jason Edwards, and Denzil Broadhurst for their technical assistance.

451 


\section{References}

Ainslie PN, Campbell IT, Frayn KN, Humphreys SM, Maclaren DPM, and Reilly T (2002). Physiological and metabolic responses to a hill walk. J Appl Physiol 92:179-187.

Ainslie PN and Ogoh S (2010). Regulation of cerebral blood flow in mammals during chronic hypoxia: a matter of balance. Exp Physiol 95:251-262.

Amann M (2012). Pulmonary system limitations to endurance exercise performance in humans. Exp Physiol $97: 311-318$

Amann M, Pegelow DF, Jacques AJ, and Dempsey JA (2007). Inspiratory muscle work in acute hypoxia influences locomotor muscle fatigue and exercise performance of healthy humans. Am J Physiol Regul Integr Comp Physiol 293:2036-2045.

Babb TG, Ranasinghe KG, Comeau LA, Semon TL, and Schwartz B (2008). Dyspnea on exertion in obese women: Association with an increased oxygen cost of breathing. Am J Respir Crit Care Med 178:116-123.

Bacon AP, Carter RE, Ogle EA, and Joyner MJ (2013). VO2max trainability and high intensity interval training in humans: A meta-analysis. PLoS One 8:e73182.

Bärtsch P (2014). Con: hypoxic cardiopulmonary exercise testing identifies subjects at risk for severe high altitude illnesses. High Alt Med Biol 15:318-320.

Bärtsch P and Swenson ER (2013). Clinical practice: Acute high-altitude illnesses. N Engl J Med 368:2294-2302.

Bassett DR and Howley ET (2000). Limiting factors for maximum oxygen uptake and determinants of endurance performance. Med Sci Sport Exerc 32:70-84.

Bernardi L, Schneider A, Pomidori L, Paolucci E, and Cogo A (2006). Hypoxic ventilatory response in successful extreme altitude climbers. Eur Respir J 27:165-171.

Bernhadt V, Wood HE, Moran RB, and Babb TG (2013). Dyspnea on exertion in obese men. Respir Physiol Neurobiol 185:241-248.

Bland M (2015). Determination of sample size. Oxford University Press, Oxford.

Borg G and Borg E (2001). A new generation of scaling methods: Level-anchored ratio scaling.28:15-45.

Bouchard C, Sarzynski MA, Rice TK, Kraus WE, Church TS, Sung YJ, Rao DC, and Rankinen T (2011). Genomic predictors of the maximal $\mathrm{O}_{2}$ uptake response to standardized exercise training programs. J Appl Physiol 110:1160-1170.

Burtscher M, Gatterer H, and Kleinsasser A (2015). Cardiorespiratory fitness of high altitude mountaineers: The underestimated prerequisite. High Alt Med Biol 16:169-170. 
Callender N, Ellerton J, and Macdonald JH (2012). Physiological demands of mountain rescue work. Emerg Med J 29:753-757.

Canouï-Poitrine F, Veerabudun K, Larmignat P, Letournel M, Bastuji-Garin S, and Richalet J-P (2014). Risk prediction score for severe high altitude illness: a cohort study. PLoS One 9:e100642.

Coquart JB, Garcin M, Parfitt G, Tourny-Chollet C, and Eston RG (2014). Prediction of maximal or peak oxygen uptake from ratings of perceived exertion. Sport Med 44:563-578.

Coquart J, Tabben M, Farooq A, Tourny C, and Eston R (2016). Submaximal, perceptually regulated exercise testing predicts maximal oxygen uptake: a meta-analysis study. Sport Med 46:885-897.

Coyle EF, Coggan AR, Hopper MK, and Walters TJ (1988). Determinants of endurance in well-trained cyclists. J Appl Physiol 64:2622-2630.

Enoka RM and Stuart DG (1992). Neurobiology of muscle fatigue. J Appl Physiol 72:1631-1648.

Eston R (2012). Use of Ratings of Perceived Exertion in Sports. Int J Sports Physiol Perform 7:175-182.

Fanchini M, Ferraresi I, Modena R, Schena F, Coutts AJ, and Impellizzeri FM (2016). Use of CR100 scale for session-RPE in soccer and interchangeability with CR10. Int J Sports Physiol Perform 11:388-392.

Ferretti G, Moia C, Thomet J, Kayser B, Physiologie D De, Universitaire CM, and Servet M (1997). The decrease of maximal oxygen consumption during hypoxia in man: a mirror image of the oxygen equilibrium curve. J Physiol 498:231-237.

Firth PG, Zheng H, Windsor JS, Sutherland AI, Imray CH, Moore GWK, Semple JL, Roach RC, and Salisbury RA (2008). Mortality on Mount Everest, 1921-2006: descriptive study. Br Med J 337:a2654.

Foster C, Florhaug JA, Franklin J, Gottschall L, Hrovatin LA, Parker S, Doleshal P, and Dodge C (2001). A new approach to monitoring exercise training. J Strength Cond Res 15:109-115.

Fulco CS, Rock PB, and Cymerman a (1998). Maximal and submaximal exercise performance at altitude. Aviat Space Environ Med 69:793-801.

Gaskill SE, Ruby BC, Walker AJ, Sanchez OA, Serfass RC, and Leon AS (2001). Validity and reliability of combining three methods to determine ventilatory threshold. Med Sci Sport Exerc 33:1841-1848.

Government of Nepal (2013). Ministry of Culture Tourism \& Civil Aviation: Nepal Tourism Statistics 2013.

Hayes AF (2013). Introduction to Mediation, Moderation and Conditional Process Analysis: A Regression-Based Approach. Guilford Press, New York.

Jackson AS, Blair SN, Mahar MT, Wier LT, Ross RM, and Stuteville JE (1990). Prediction of functional aerobic capacity without exercise testing. Med Sci Sport Exerc 22:863-870. 
Jakobsen MD, Sundstrup E, Brandt M, Jay K, Aagaard P, and Andersen LL (2015). Physical exercise at the workplace reduces perceived physical exertion during healthcare work: cluster randomized controlled trial. Scand J Public Health 43:1-8.

Karinen HM, Peltonen JE, Kähönen M, and Tikkanen HO (2010). Prediction of acute mountain sickness by monitoring arterial oxygen saturation during ascent. High Alt Med Biol 11:325-332.

Lazio MP, Roo JD Van, Pesce C, Malik S, and Courtney DM (2010). Postexercise peripheral oxygen saturation after completion of the 6-minute walk test predicts successfully reaching the summit of Aconcagua. Wilderness Environ Med 21:309-317.

Lhuissier FJ, Brumm M, Ramier D, and Richalet J-P (2012). Ventilatory and cardiac responses to hypoxia at submaximal exercise are independent of altitude and exercise intensity. J Appl Physiol 112:566-570.

MacInnis MJ, Nugent SF, Macleod KE, and Lohse KR (2015). Methods to estimate VO2max upon acute hypoxia exposure. Med Sci Sport Exerc 47:1869-1876.

Marconi C, Marzorati M, Grassi B, Basnyat B, Colombini A, Kayser B, and Cerretelli P (2004). Second generation Tibetan lowlanders acclimatize to high altitude more quickly than Caucasians. J Physiol 5562:661-671.

Matthews CE, Heil DP, Freedson PS, and Pastides H (1999). Classification of cardiorespiratory fitness without exerise testing. Med Sci Sport Exerc 31:486-93.

Milanović Z, Sporiš G, and Weston M (2015). Effectiveness of high-intensity interval training (HIT) and continuous endurance training for VO2max improvements: A systematic review and meta-analysis of controlled trials. Sport Med 45:1469-1481.

Mollard P, Woorons X, Letournel M, Lamberto C, Favret F, Pichon A, Beaudry M, and Richalet J-P (2007). Determinants of maximal oxygen uptake in moderate acute hypoxia in endurance athletes. Eur J Appl Physiol 100:663-673.

Oliver SJ, Sanders SJ, Williams CJ, Smith ZA, Lloyd-Davies E, Roberts R, Arthur C, Hardy L, and Macdonald JH (2012). Physiological and psychological illness symptoms at high altitude and their relationship with acute mountain sickness: a prospective cohort study. J Travel Med 19:210-219.

Pandolf KB, Givoni B, and Goldman RF (1977). Predicting energy expenditure with loads while standing or walking very slowly. J Appl Physiol 43:577-581.

Pescatello L, Arena R, Riebe D, and Thompson P (2013). American College of Sports Medicine's guidelines for exercise testing and prescription. Wolters Kluwer/Lippincott Williams \& Wilkins Health, Philadelphia.

Puthon L, Bouzat P, Rupp T, Robach P, Favre-Juvin A, and Verges S (2015). Physiological characteristics of elite 
Rathat C, Richalet J-P, Herry J-P, and Larmignat P (1992). Detection of high-risk subjects for high altitude diseases. Int J Sports Med 13:S76-S78.

Richalet J-P and Canouï-Poitrine F (2014). Pro: hypoxic cardiopulmonary exercise testing identifies subjects at risk for severe high altitude illnesses. High Alt Med Biol 15:315-317.

Richalet J-P, Larmignat P, Poitrine E, Letournel M, and Canouï-Poitrine F (2012). Physiological risk factors for severe high-altitude illness: A prospective cohort study. Am J Respir Crit Care Med 185:192-198.

Richalet J-P and Lhuissier FJ (2015). Aging, tolerance to high altitude, and cardiorespiratory response to hypoxia. High Alt Med Biol 16:117-124.

Roach RC, Bärtsch P, Oelz O, and Hackett PH (1993). Lake Louise AMS scoring consensus committee: the Lake Louise acute mountain sickness scoring system. In: Hypoxia and molecular medicine. JR Sutton, C Houston, and G Coates, eds. Charles S. Houston, Burlington, Vermont; pp. 272-274.

Schneider M, Bernasch D, Weymann J, Holle R, and Bärtsch P (2002). Acute mountain sickness: influence of susceptibility, preexposure, and ascent rate. Med Sci Sport Exerc 34:1886-1891.

Schoene RB, Lahiri S, Hackett PH, Peters RM, Milledge JS, Pizzo CJ, Sarnquist FH, Boyer SJ, Graber DJ, Maret KH, and West JB (1984). Relationship of hypoxic ventilatory response to exercise performance on Mount Everest. J Appl Physiol 56:1478-1483.

Terry PC, Lane AM, Lane HJ, and Keohane L (1999). Development and validation of a mood measure for adolescents: POMS-A. J Sports Sci 17:861-872.

Van Thienen R and Hespel P (2016). Enhanced muscular oxygen extraction in athletes exaggerates hypoxemia during exercise in hypoxia. J Appl Physiol 120:351-361. 
Table 1. Physiological and perceptual responses to step tests.

\begin{tabular}{|c|c|c|c|c|c|c|}
\hline & \multicolumn{3}{|c|}{ Fixed-workload step test } & \multicolumn{3}{|c|}{ Perceptually-regulated step test } \\
\hline & & Acute & Chronic & & Acute & Chronic \\
\hline & Sea level & normobaric & high & Sea level ${ }^{1}$ & normobaric & high \\
\hline & & hypoxia & altitude & & hypoxia $^{1}$ & altitude \\
\hline RPE & $20(7)$ & $30(11)$ & $46(23)$ & $35^{2}$ & $35^{2}$ & $35^{2}$ \\
\hline Step rate & $24^{2}$ & $24^{2}$ & $24^{2}$ & $36(7)$ & $30(5)$ & $27(6)$ \\
\hline Heart rate (bpm) & $116(16)$ & $143(19)$ & $132(19)$ & $145(23)$ & $157(20)$ & $135(15)$ \\
\hline $\mathrm{SpO}_{2}(\%)$ & $97(3)$ & $70(5)$ & $75(5)$ & $96(5)$ & $70(4)$ & $72(4)$ \\
\hline Ventilation $(\mathrm{L} / \mathrm{min})$ & $33(7)$ & $47(11)$ & $40(10)$ & - & - & - \\
\hline
\end{tabular}

$\mathrm{N}=44$. Values are mean (SD). ${ }^{1}$ Conducted as familiarization trials, but data included here for completeness; ${ }^{2} \mathrm{By}$ design, values are the same in all participants for this variable. 
Table 2. Summary of trekking demands and relationship to sea level $\dot{\mathbf{V}} \mathbf{O}_{2 \max }$

\begin{tabular}{|c|c|c|c|}
\hline \multirow{2}{*}{ Trekking Variable } & \multirow{2}{*}{ Ascent to Base Camp } & \multicolumn{2}{|c|}{ Relationship to $\dot{\mathbf{V}} \mathbf{O}_{2 \max }$} \\
\hline & & $\mathbf{r}$ & $\mathbf{p}$ \\
\hline Walking speed $\left(\mathrm{km} \cdot \mathrm{h}^{-1}\right)$ & $1.5(0.3)$ & 0.22 & 0.17 \\
\hline External load (kg) & $11.1(2.4)$ & 0.15 & 0.37 \\
\hline Energy expenditure (kJ) & $2298(584)$ & -0.21 & 0.20 \\
\hline Heart rate (bpm) & $126(14)$ & -0.03 & 0.86 \\
\hline Session RPE & $51(20)$ & $-0.43 * *$ & 0.005 \\
\hline Relative exertion $\left(\mathrm{RPE} \cdot \mathrm{kJ}^{-1} \cdot \mathrm{min}^{-1}\right)$ & $5.9(2.6)$ & $-0.35^{*}$ & 0.03 \\
\hline
\end{tabular}




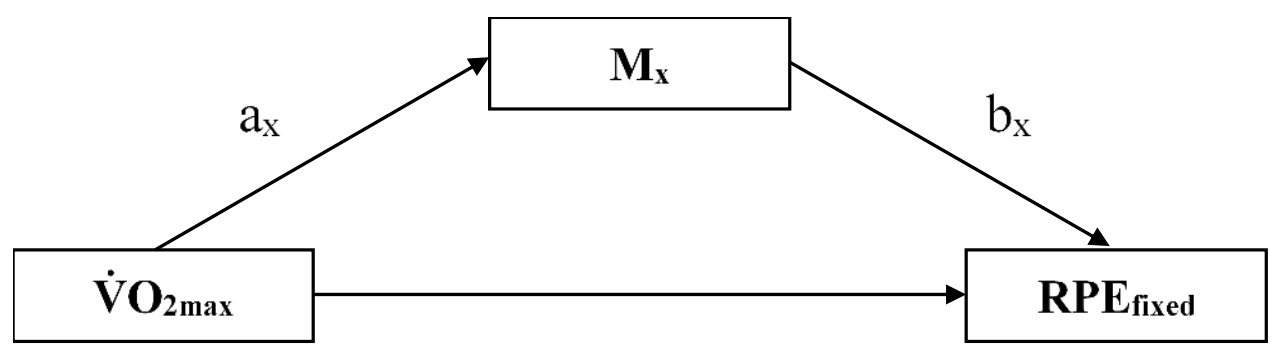

\begin{tabular}{llll}
\hline \multicolumn{1}{c}{ Variable $\left(\mathbf{M}_{\mathbf{x}}\right)$} & $\mathbf{a}_{\mathbf{x}}\left(\dot{\mathbf{V}} \mathbf{O}_{2 \mathbf{m a x}} \rightarrow \mathbf{M}_{\mathbf{x}}\right)$ & $\mathbf{b}_{\mathbf{x}}\left(\mathbf{M}_{\mathbf{x}} \rightarrow \mathbf{R P E} \mathbf{E}_{\mathbf{f i x e d}}\right)$ & Indirect effect $\left(\mathbf{a b} \mathbf{b}_{\mathbf{x}}\right)$ \\
\hline $\begin{array}{l}\text { Acute normobaric hypoxia } \\
\text { HVRe }\end{array}$ & $-0.27(-0.58 ; 0.04)$ & $0.21(-0.07 ; 0.49)$ & $-0.06(-0.25 ; 0.01)$ \\
HCRe & $0.37(0.06 ; 0.69)^{*}$ & $-0.05(-0.34 ; 0.23)$ & $-0.02(-0.18 ; 0.08)$ \\
Chronic high altitude exposure & & & \\
Exercise ventilation reserve & $0.85(0.60 ; 1.10)^{* *}$ & $-0.29(-0.72 ; 0.13)$ & $-0.25(-0.55 ; 0.33)$ \\
Ventilatory efficiency & $0.59(0.25 ; 0.93)^{* *}$ & $-0.14(-0.46 ; 0.18)$ & $-0.08(-0.28 ; 0.11)$ \\
Chronic change in heart rate & $0.42(0.12 ; 0.72)^{*}$ & $-0.23(-0.51 ; 0.05)$ & $-0.10(-0.32 ; 0.00)$ \\
\hline
\end{tabular}

571 If a variable $\mathrm{M}_{\mathrm{x}}$ explains (mediates) the relationship between $\dot{\mathrm{V}}_{2 \max }$ and $\mathrm{RPE}_{\mathrm{fixed}}$, the indirect effect $\left(\mathrm{ab} \mathrm{b}_{\mathrm{x}}\right.$ ) should

572 not span zero. The values suggest that HCRe and chronic change in heart rate tended or did significantly explain

573 (positively mediate) the relationship between $\dot{\mathrm{V}}_{2 \max }$ and $\mathrm{RPE}_{\text {fixed. }}$. In contrast $\mathrm{HVRe}$ tended to explain (negatively

574 mediate) the relationship between $\dot{\mathrm{V}}_{2 \max }$ and $\mathrm{RPE}_{\text {fixed. }}$. Values are standardized regression coefficients and $95 \%$

575 confidence intervals (lower limit; upper limit) for direct effects of $\dot{\mathrm{V}} \mathrm{O}_{2 \max }$ on mediators $\left(\mathrm{a}_{\mathrm{x}}\right.$ ), direct effects of 576 mediators on $\mathrm{RPE}_{\text {fixed }}\left(\mathrm{b}_{\mathrm{x}}\right)$, and indirect effects of $\dot{\mathrm{V}} \mathrm{O}_{2 \max }$ on $\mathrm{RPE}_{\text {fixed }}$ through mediators $\left(\mathrm{ab}_{\mathrm{x}}\right)$. *p $<0.05$; **p $<$ 0.01 . 


\begin{tabular}{|c|c|c|c|c|c|c|c|c|}
\hline Model & Variable & B & SE B & $\boldsymbol{\beta}$ & $r^{2}$ & $\mathbf{p}$ & $r^{2}$ change & $\begin{array}{c}p \text { for } \\
r^{2} \text { change }\end{array}$ \\
\hline \multicolumn{9}{|c|}{ Analysis 1} \\
\hline 1 & Questionnaire $\dot{\mathrm{VO}}_{2 \max }$ & -1.85 & 0.40 & $-0.62 * * *$ & 0.39 & $<0.001$ & & \\
\hline \multirow[t]{2}{*}{2} & Questionnaire $\dot{\mathrm{V}}_{2 \max }$ & -0.61 & 0.59 & -0.21 & 0.47 & $<0.001$ & & \\
\hline & Laboratory $\dot{\mathrm{V}}_{2 \max }$ & -1.49 & 0.56 & $-0.53 *$ & & & $0.11 * *$ & 0.01 \\
\hline \multicolumn{9}{|c|}{ Analysis 2} \\
\hline 1 & Laboratory $\dot{\mathrm{V}}_{2 \max }$ & -1.91 & 0.35 & $-0.69 * * *$ & 0.47 & $<0.001$ & & \\
\hline \multirow[t]{4}{*}{2} & Laboratory $\dot{\mathrm{V}}_{2 \max }$ & -1.55 & 0.41 & $-0.56^{* *}$ & 0.54 & $<0.001$ & & \\
\hline & HVRe & 9.81 & 8.00 & 0.18 & & & 0.07 & 0.22 \\
\hline & HCRe & -8.80 & 7.64 & -0.17 & & & & \\
\hline & $\Delta \mathrm{SpO}_{2} \mathrm{e}$ & -0.67 & 0.57 & -0.16 & & & & \\
\hline
\end{tabular}

In analysis 1 , model 1 shows the utility of questionnaire-based estimation of $\dot{\mathrm{V}} \mathrm{O}_{2 \max }$, whilst model 2 shows the additional utility of laboratory-assessed $\mathrm{V}_{2}$ max (note the significant $r^{2}$ in model 1 and $r^{2}$ change value in model 2). In analysis 2 , model 1 shows the utility of laboratory-assessed $\dot{\mathrm{V}}_{2 \max }$, whilst model 2 shows the lack of benefit of additional hypoxic exercise testing (note the significant $r^{2}$ in model 1 but insignificant $r^{2}$ change value in model 2). $B$, unstandardized beta coefficient (the magnitude of the effect in raw units); SE B, standard error of $B$; $\beta$, standardized beta coefficient (the magnitude of the effect in standardized units, allowing comparison between variables). ${ }^{*} \mathrm{p}<0.05 ; * * \mathrm{p}<0.01 ; * * \mathrm{p}<0.001$. 


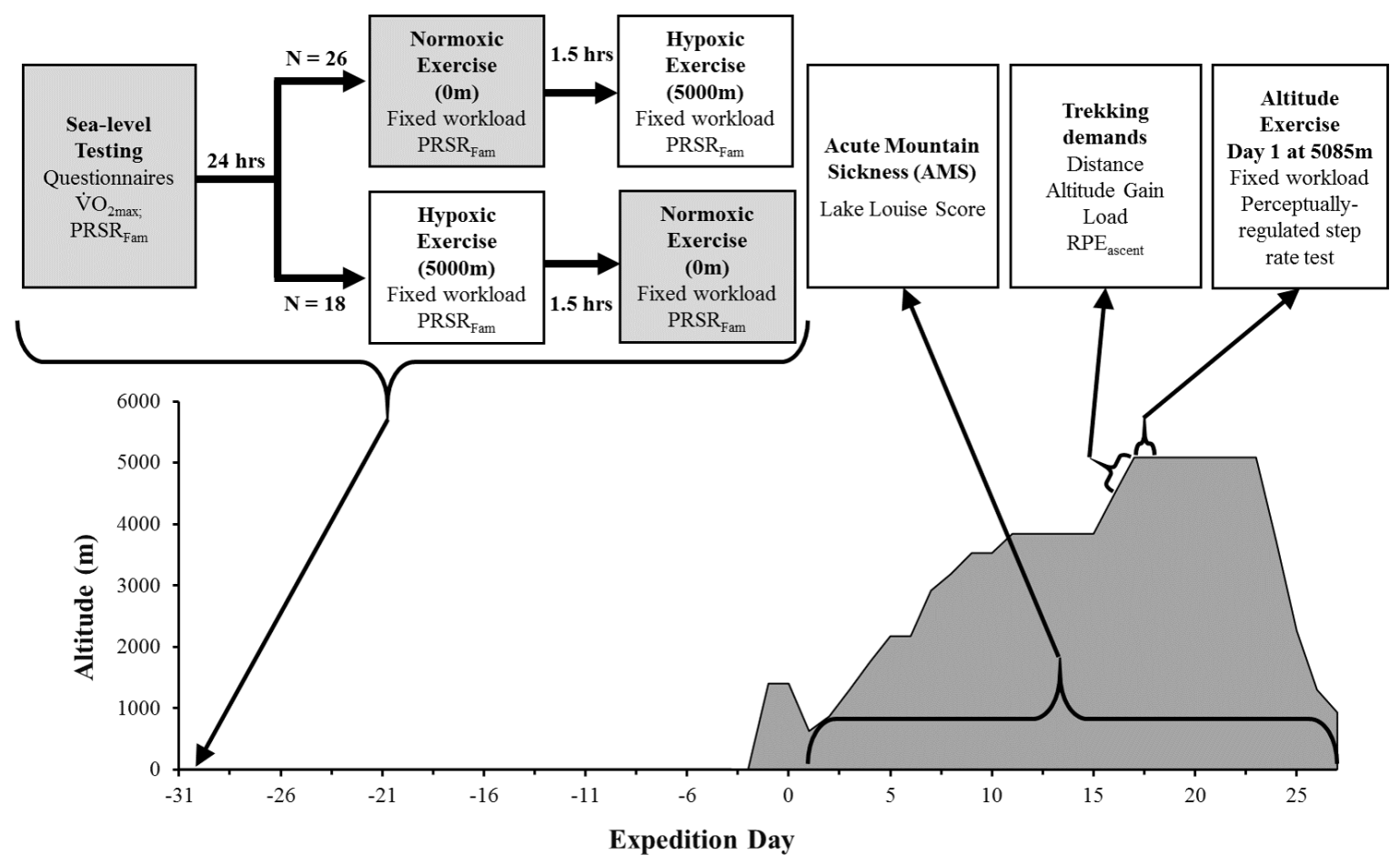

591 Figure 1. Schematic representation of study protocol. Grey boxes indicate procedures undertaken in normoxia,

592 white boxes indicate procedures undertaken in hypoxia. PRSR $\mathrm{Fam}$, Perceptually-regulated step rate test

593 familiarization; LLS, Lake Louise Score; Load, External load for the trekking session (kg); $\mathrm{RPE}_{\text {ascent }}$, Rating of 594 perceived exertion on ascent to Base Camp. 
A

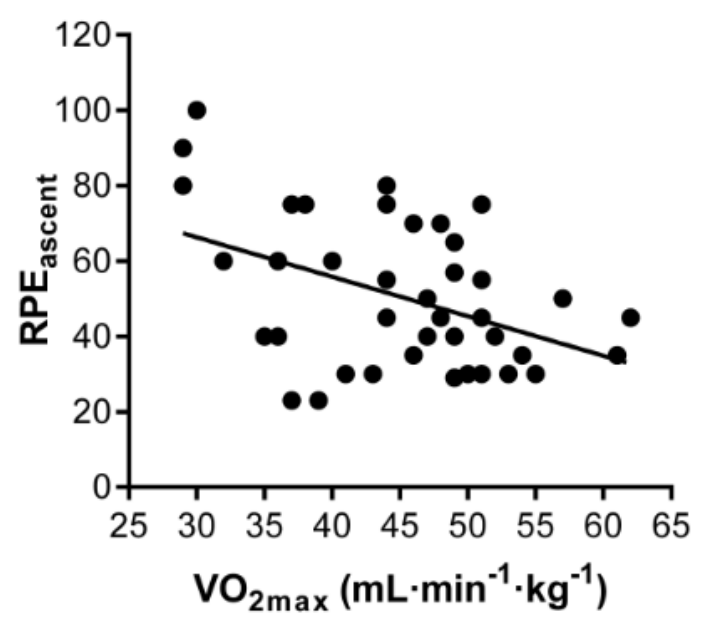

C

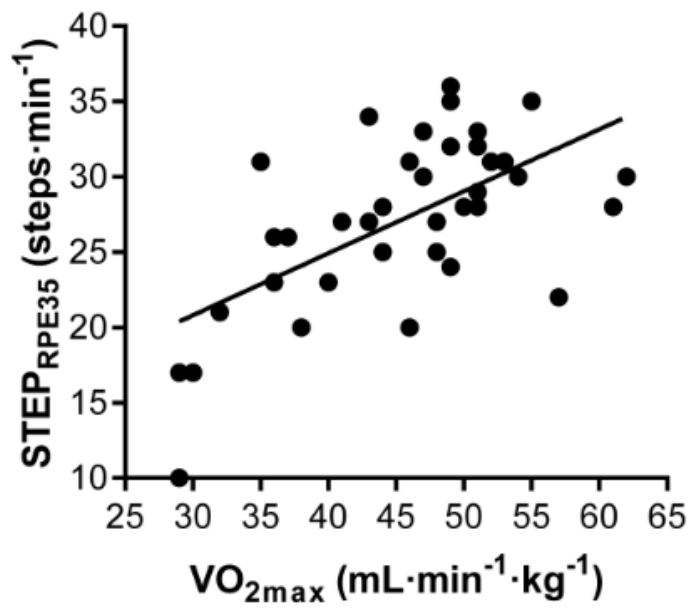

B

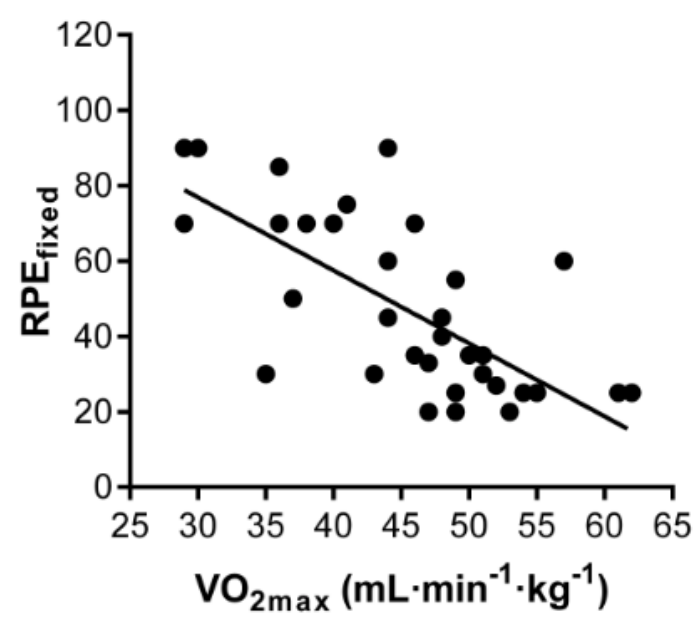

D

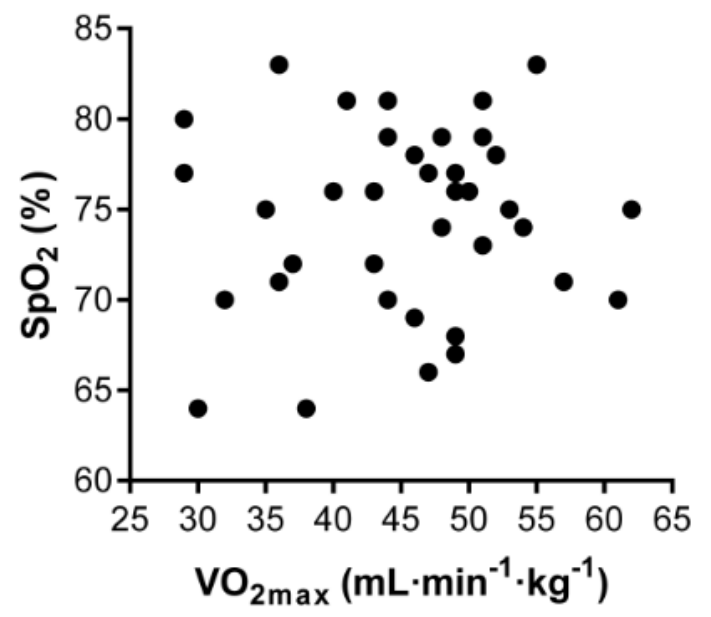

597 Figure 2. Relationship between sea-level fitness $\left(\dot{\mathrm{V}}_{2 \max }\right)$ and submaximal exercise at altitude. Greater sea-level fitness was associated with (A) reduced session RPE from ascent to Base Camp (RPE ascent; $r=-0.43 ; p=0.005$ ), (B) reduced RPE at a fixed workload ( $\mathrm{RPE}_{\text {fixed }} ; r=-0.69 ; p<0.001$ ), and (C) greater step rate during perceptuallyregulated exercise ( $\left.\mathrm{STEP}_{\mathrm{RPE} 35} ; r=0.62 ; p<0.001\right)$. Sea-level fitness was not related to (D) oxygen saturation during fixed-workload step test at altitude $\left(\mathrm{SpO}_{2} ; r=0.07 ; p=0.67\right)$. 
A

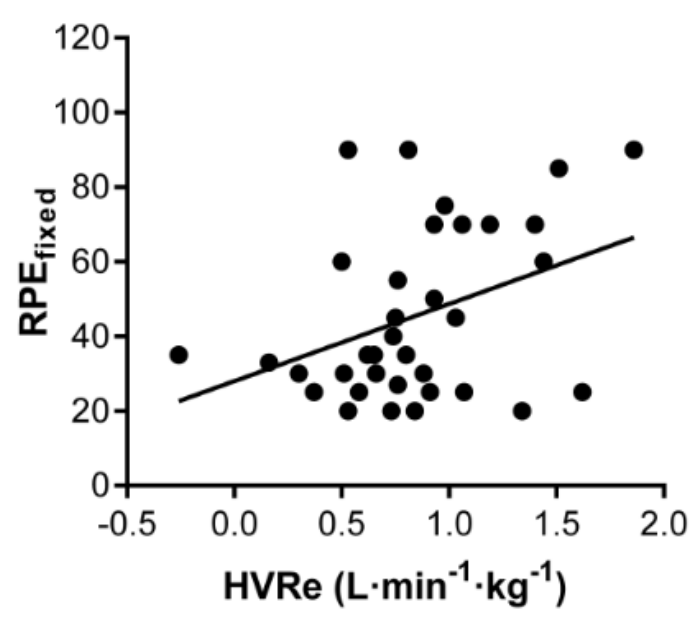

C

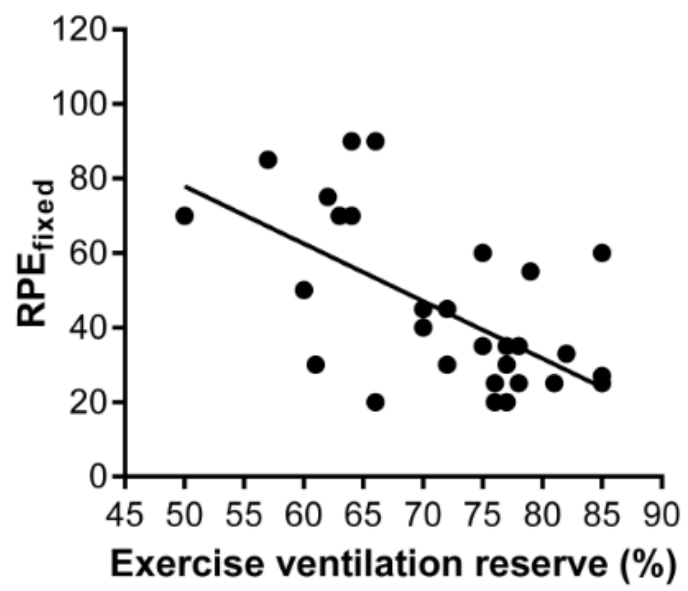

B

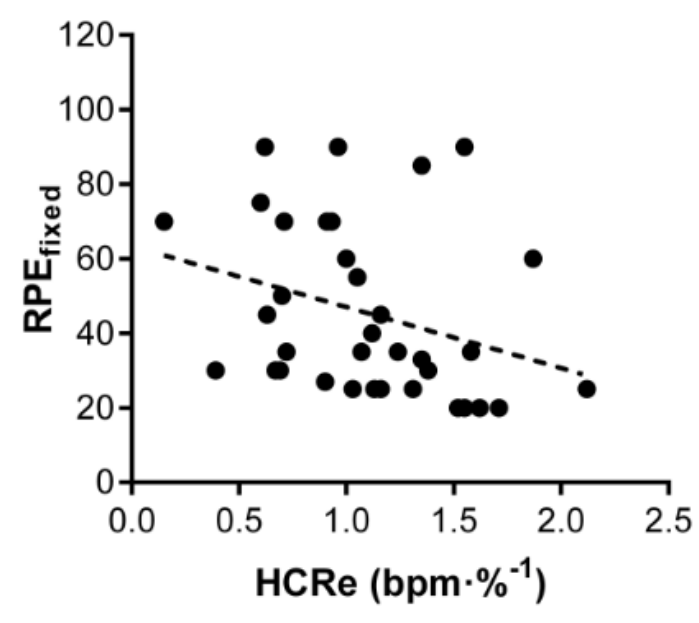

D

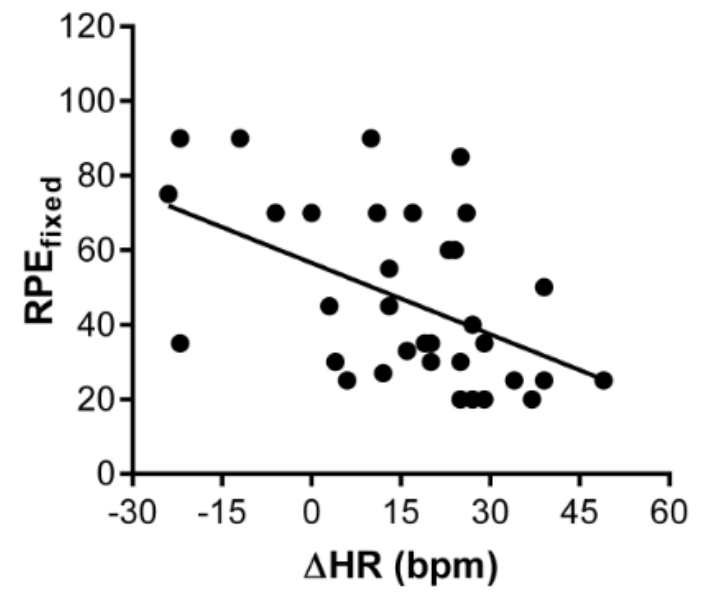

603

Figure 3. Relationships between ventilatory and cardiac responses to acute and chronic high altitude with sense of effort at altitude ( $\mathrm{RPE}_{\text {fixed }}$ ). Reduced $\mathrm{RPE}_{\text {fixed }}$ was associated with (A) reduced hypoxic ventilatory response (HVRe; $r=0.38 ; p=0.02$ ), (B) elevated hypoxic cardiac response (HCRe; $r=-0.31 ; p=0.07$ ), (C) elevated exercise ventilation reserve at altitude $(r=-0.60 ; p<0.001)$, and (D) elevated chronic change in heart rate $(r=-$ $0.49 ; p=0.003)$. 
A

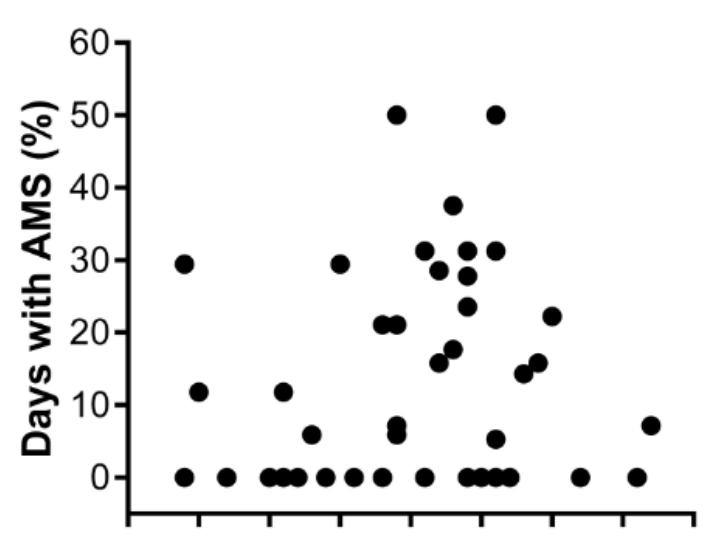

B

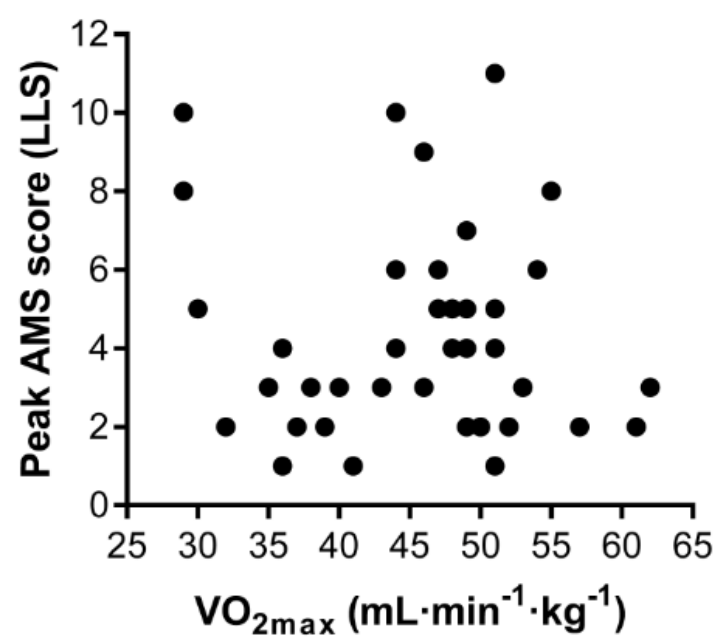

610

611 Figure 4. Sea-level fitness $\left(\mathrm{V}_{2 \max }\right)$ was not related to (A) percent of trekking days with clinically-defined AMS $612(r=0.13 ; p=0.41)$, or $(\mathrm{B})$ peak AMS score $(r=-0.05 ; p=0.74)$.

613 